\title{
Study of Dielectric and Piezoelectric Properties in the Ternary System $\mathrm{Pb}_{0.98} \mathrm{Ca}_{0.02}\left[\left\{\left(\mathrm{Zr}_{0.52} \mathrm{Ti}_{0.48}\right)_{0.98}\left(\mathrm{Cr}_{0.5}^{3+}, \mathrm{Ta}_{0.5}^{5+}\right)_{0.02}\right\}_{1-\mathrm{z}} \mathbf{P}_{\mathrm{z}}\right] \mathrm{O}_{3}$ Doping Effects
}

\author{
Hamzioui Louanes ${ }^{1,2 *}$, Kahoul Fares ${ }^{1,2}$, Abdessalem Nora ${ }^{1}$, Boutarfaia Ahmed ${ }^{1,2}$ \\ ${ }^{1}$ Laboratoire de Chimie Appliquée, Université de Biskra, Biskra, Algérie; ${ }^{2}$ Département de Science de la Matière, Université de \\ Ouargla, Ouargla, Algérie. \\ Email: \{hamzioui_louanes, aboutarfaia\}@yahoo.fr
}

Received November $7^{\text {th }}, 2011$; revised December $8^{\text {th }}, 2011$; accepted December $29^{\text {th }}, 2011$

\begin{abstract}
The effects of $\mathrm{P}_{2} \mathrm{O}_{5}$ oxide on microstructure, dielectric and piezoelectric properties of $\mathrm{Pb}_{0.98} \mathrm{Ca}_{0.02}\left[\left\{\left(\mathrm{Zr}_{0.52} \mathrm{Ti}_{0.48}\right)_{0.98}\left(\mathrm{Cr}_{1 / 2}^{3+}\right.\right.\right.$, $\left.\left.\left.\mathrm{Ta}_{1 / 2}^{5+}\right)_{0.02}\right\}_{1-\mathrm{z}} \mathrm{P}_{\mathrm{z}}\right] \mathrm{O}_{3}$ ternary ceramics were investigated. Specimens with various contents of $\mathrm{P}_{2} \mathrm{O}_{5}$ from 0 to $12 \mathrm{wt} \%$ were prepared by a conventional oxide mixing technique. The effect of $\mathrm{P}_{2} \mathrm{O}_{5}$ doping with regard to the development of the crystalline phase, density, microstructure, dielectric, ferroelectric and piezoelectric characteristics has been investigated. It has been found that the sintering temperature of piezoelectric $\left.\mathrm{Pb}_{0.98} \mathrm{Ca}_{0.02}\left[\left\{\mathrm{Zr}_{0.52} \mathrm{Ti}_{0.48}\right)_{0.98}\left(\mathrm{Cr}_{1 / 2}^{3+}, \mathrm{Ta}_{1 / 2}^{5+}\right)_{0.02}\right\}_{1-\mathrm{z}} \mathrm{P}_{\mathrm{z}}\right] \mathrm{O}_{3}$ can be reduced by phosphorus addition without compromising the dielectric properties. A sintered density of $94 \%$ of the theoretical density was obtained for $4 \mathrm{wt} \% \mathrm{P}_{2} \mathrm{O}_{5}$ addition after sintering at $1050^{\circ} \mathrm{C}$ for $4 \mathrm{~h}$. Ceramics sintered at $1050^{\circ} \mathrm{C}$ with $4 \mathrm{wt} \% \mathrm{P}_{2} \mathrm{O}_{5}$ achieve excellent properties, which are as follows: $\mathrm{kp}=0.73, \rho=0.09 \times 10^{+4}(\Omega \cdot \mathrm{cm}), \varepsilon_{\mathrm{r}}=$ $18800, \tan \delta=0.0094$ and $\mathrm{Tc}=390^{\circ} \mathrm{C}$.
\end{abstract}

Keywords: PZT; Piezoelectricity; Electronic Materials; Dielectric Properties; Methods Physico-Chemical of Analysis

\section{Introduction}

Lead-based perovskite-type solid solutions consisting of the ferroelectric and relaxor materials have attracted a growing fundamental and practical interest because of their excellent dielectric, piezoelectric and electrostrictive properties which are useful in actuating and sensing applications [1,2]. However, the sintering of PZT at high temperatures gives rise to a lead loss, which drastically degrades the device performance. Generally, a lead loss at high temperatures can be prevented by atmospherecontrolled sintering of PZT. However, such composition requires sintering at a high temperature $\left(>1250^{\circ} \mathrm{C}\right)$ in a controlled atmosphere to contain lead volatilization so as to avoid a shift in composition. To get around the problem, different sintering aids have been tried by various workers [3-5]. However, for practical applications, such sintering aids need proper selection so that the electrical and piezoelectric properties of the ceramics do not degrade.

The dielectric constants increased with the addition of $\mathrm{NiO}, \mathrm{Fe}_{2} \mathrm{O}_{3}, \mathrm{Gd}_{2} \mathrm{O}_{3}, \mathrm{Nb}_{2} \mathrm{O}_{5}$ or $\mathrm{WO}_{3}$ and decreased with

*Corresponding author.
$\mathrm{Cr}_{2} \mathrm{O}_{3}$ or $\mathrm{MnO}_{2}$ addition [6-12]. Duran et al. studied the effect of $\mathrm{MnO}$ addition on the sintering and piezoelectric properties of Sm-modified lead titanate ceramics. The maximum density observed was $96.8 \%$ of the theoretical densit for $1 \% \mathrm{MnO}$ addition at a sintering temperature of $1150^{\circ} \mathrm{C}$ [13]. The main role of dopants is generally improved physical and mechanical properties of these materials. This work aims at, to study the influence of $\mathrm{P}_{2} \mathrm{O}_{5}$ on the properties dielectric and piezoelectric of a ceramics material of general formula: $\mathrm{Pb}_{0.98} \mathrm{Ca}_{0.02}\left[\left(\mathrm{Zr}_{0.52} \mathrm{Ti}_{0.48}\right)_{0.98}\right.$ $\left.\left(\mathrm{Cr}_{0.5}^{3+}, \mathrm{Ta}_{0.5}^{5+}\right)_{0.02}\right] \mathrm{O}_{3}$ and of structure perovskite.

\section{Experimental Procedure}

The compositions used for the present study were $\mathrm{Pb}_{0.98}$ $\mathrm{Ca}_{0.02}\left[\left\{\left(\mathrm{Zr}_{0.52} \mathrm{Ti}_{0.48}\right)_{0.98}\left(\mathrm{Cr}_{0.5}^{3+}, \mathrm{Ta}_{0.5}^{5+}\right)_{0.02}\right\}_{1-\mathrm{z}} \mathrm{P}_{\mathrm{z}}\right] \mathrm{O}_{3}$ with $\mathrm{z}$ varying as $0,2,4,6,8,10$ and $12 \mathrm{wt} \%$ respectively. The samples were prepared by a conventional oxide mixing technique. The appropriate amounts of $\mathrm{PbO}(99.9 \%)$, $\mathrm{TiO}_{2}$ (99.9\%), $\mathrm{ZrO}_{2}$ (99.0\%), $\mathrm{Ta}_{2} \mathrm{O}_{5}$ (99.9\%), $\mathrm{CaO}$ (99.9\%), $\mathrm{Cr}_{2} \mathrm{O}_{3}(99.9 \%)$ and $\mathrm{P}_{2} \mathrm{O}_{5}(99.9 \%)$ powders were weighed and mixed by ball milling with partially stabilized zirconia balls as media in isopropyl alcohol for $6 \mathrm{~h}$. 
After drying, the mixture was calcined in a covered alumina crucible at $800^{\circ} \mathrm{C}$ for $4 \mathrm{~h}$. The calcined powders were again ball milled for $24 \mathrm{~h}$. The resulting powders were uniaxially compacted into pellets of $10 \mathrm{~mm}$ in diameter at a pressure of $5 \mathrm{MPa}$, followed by isostatically pressing at $150 \mathrm{MPa}$. To investigate their sintering behavior, the specimens were sintered in a sealed alumina crucible at temperatures ranging from $1000^{\circ} \mathrm{C}$ to $1180^{\circ} \mathrm{C}$ for $2 \mathrm{~h}$. To limit $\mathrm{PbO}$ loss from the pellets, a PbO-rich atmosphere was maintained by placing an equimolar mix ture of $\mathrm{PbO}$ and $\mathrm{ZrO}_{2}$ inside the crucible. The weight loss of a well-sintered specimen was less than $0.5 \mathrm{wt} \%$, thus a $0.5 \mathrm{wt} \%$ excess $\mathrm{PbO}$ was added to compensate for the lead loss during sintering. The bulk density was measured using the Archimedean method. The sintered compounds are carefully ground, then analyzed by the scanning electron microscopy (SEM) is a technical for estimating the size distribution, the average size of grains after sintering and qualitatively assess the presence of porosity. The micrographics are made using a Microscope JMS 6400. To investigate the electrical properties, the sintered disks were lapped on their major faces, and then sliver electrodes were deposited with a low temperature paste at $700^{\circ} \mathrm{C}$ for $30 \mathrm{~min}$. The piezoelectric samples were poled in a silicone oil bath at $100^{\circ} \mathrm{C}$ by applying $20 \mathrm{kV} / \mathrm{cm}$ for $20 \mathrm{~min}$. then cooling them under the same electric field. They were aged for $24 \mathrm{~h}$ prior to testing. The temperature dependence of dielectric properties was measured at temperatures ranging from room temperature to $420^{\circ} \mathrm{C}$ with a heating rate of $2{ }^{\circ} \mathrm{C} / \mathrm{min}$ using an impedance analyzer-HP4192A, Hewlett-Packard, Palo Alto, CA. The electromechanical coupling factor, $k p$, was determined by the resonance and antiresonance technique using another impendence analyzer (SI1260 Impedance/Gain-Phase Analyzer, Solartron, UK). $(k p=[2.51(f a-f r) / f r)]^{1 / 2}$, where $f r$ and $f a$ are the resonance and anti-resonance frequencies, respectively [14]. Variation of the dielectric constant $\varepsilon_{\mathrm{r}}$, resistivity and also the angle of the losses were examined by using a measuring bridge type RLC (bridge Schering) depending on temperature, concentration, the frequency.

\section{Results and Discussion}

\subsection{Sintered Density}

Figure 1(a) shows the variation of density with sintering temperature and the amount of $\mathrm{P}_{2} \mathrm{O}_{5}$ addition. This curves show the similar variation trend with increasing sintering temperature. The density of specimens sintered at $1050^{\circ} \mathrm{C}$ showed the maximum value of $7.52 \mathrm{~g} \cdot \mathrm{cm}^{-3}$ at $4 \mathrm{wt} \%$ $\mathrm{P}_{2} \mathrm{O}_{5}$ and then was decreased after the maximum value. This variation is mainly attributed to the formation of liquid phase of excess $\mathrm{PbO}$ that improves densification of

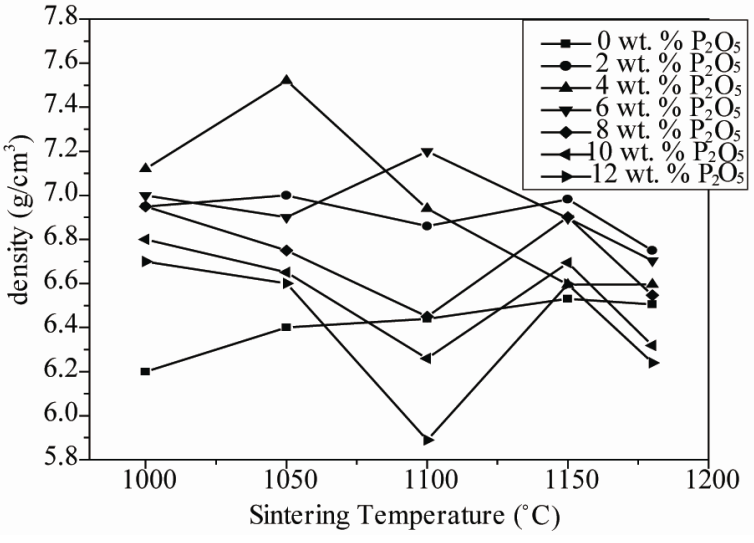

(a)

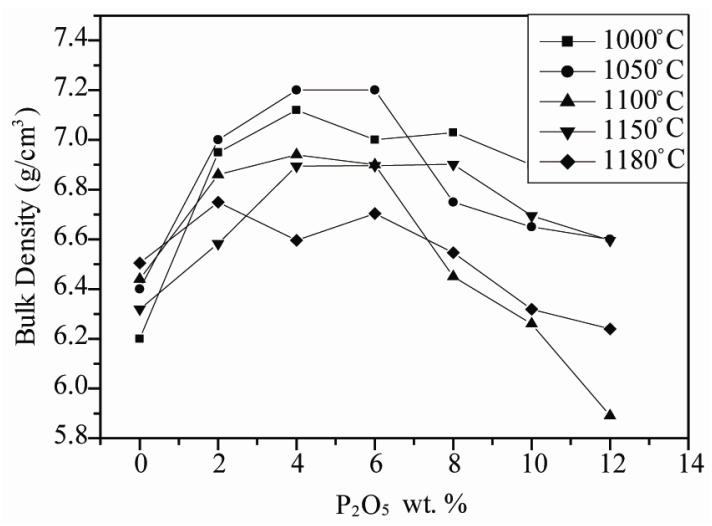

(b)

Figure 1. (a) Variation of the density of PZT-CCT samples with sintering temperature at different $\mathrm{P}_{2} \mathrm{O}_{5}$ addition; (b) Variation of bulk density of sintered PZT-CCT samples with $\mathrm{P}_{2} \mathrm{O}_{5}$ addition at different sintering temperature.

the ceramics. However, a large amount of this liquid phase leads to low density which may result from the formation of voids [15]. The densities of the sintered pellets are shown in Figure 1(b). From this figure, it is evident that initially the bulk density (as a percentage of theoretical density) of the pellets decreases with $1 \mathrm{wt} \%$ $\mathrm{P}_{2} \mathrm{O}_{5}$ addition, then also with an increasing amount of $\mathrm{P}_{2} \mathrm{O}_{5}$ addition up to $4.0 \mathrm{wt} \%$, the bulk density increased and then greater than $4.0 \mathrm{wt} \% \mathrm{P}_{2} \mathrm{O}_{5}$ addition, the density again decreased. This behavior can be explained by decomposition of $\mathrm{P}_{2} \mathrm{O}_{5}$ (melting point around $570^{\circ} \mathrm{C}$ ) can aid in liquid-phase sintering. Initially, the density of the pellets decreased on addition of $4 \mathrm{wt} \% \mathrm{P}_{2} \mathrm{O}_{5}$, because the amount of liquid formed was probably too low to get an appreciable densification. With increasing $\mathrm{P}_{2} \mathrm{O}_{5}$, the liquid-phase sintering dominated and was optimum for 4 $\mathrm{wt} \% \mathrm{P}_{2} \mathrm{O}_{5}$ addition leading to maximum densification. With a higher amount of $\mathrm{P}_{2} \mathrm{O}_{5}$ addition, the densification again decreased because there should be an optimum amount of liquid above which densification is inhibited 
due to the formation of a thick coating of the liquid around the grains [16]. Recently, Saha et al. [17] reported that a small amount of phosphorous addition $\left(\right.$ as $\left.\mathrm{P}_{2} \mathrm{O}_{5}\right)$ can improve the sintering of the PZT ceramics.

\subsection{Study of Morphological}

Figure 2 shows SEM microstructures of the fracture surfaces of samples sintered at various temperatures. The

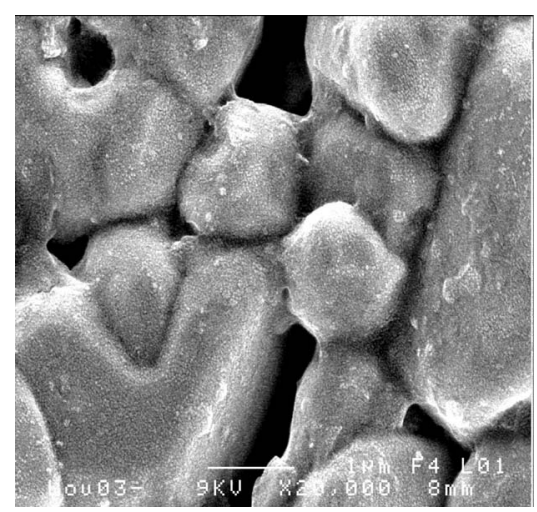

(a)

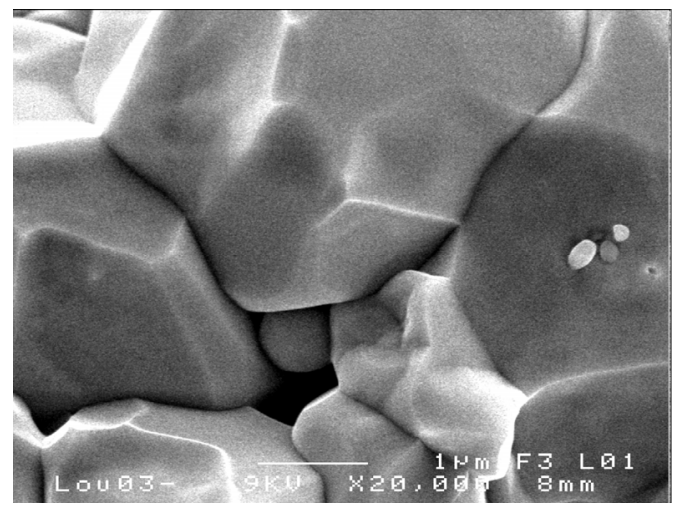

(b)

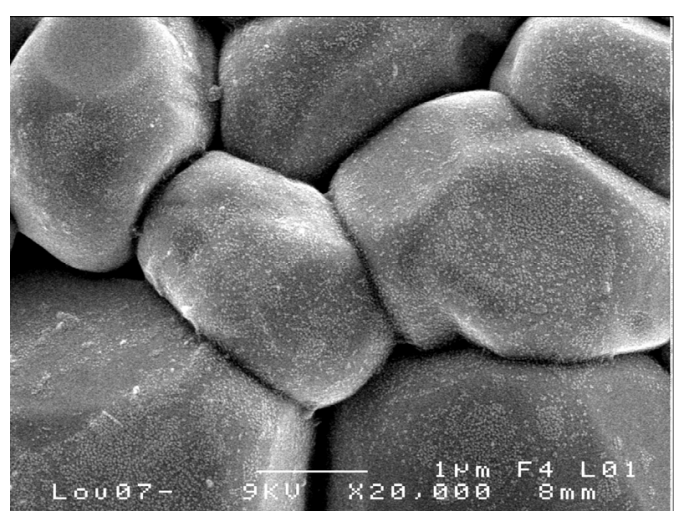

(c)

Figure 2. SEM micrographs of $\mathrm{Pb}_{0.98} \mathrm{Ca}_{0.02}\left[\left(\mathrm{Zr}_{0.52} \mathbf{T i}_{0.48}\right)_{0.98}\right.$ $\left(\mathrm{Cr}_{0.5}^{3+}, \mathrm{Ta}_{0.5}^{5+}\right)_{0.02} \mathrm{JO}_{3}$ specimens doped with $4 \mathrm{wt} \% \mathrm{P}_{2} \mathrm{O}_{5}$ and sintered at (a) $1000^{\circ} \mathrm{C}$, (b) $1050^{\circ} \mathrm{C}$ and (c) $1100^{\circ} \mathrm{C}$. distributions in the grain shape and size of the samples are rather uniform. All the samples showed an intergranular fracture mechanism indicating that the grain boundaries are mechanically weaker than the grains. These samples appear very dense and of a homogeneous granular structure, the three samples seem homogeneous and there do not seem to be grains of the pyrochlore phase which are identifiable by their pyramidal form. It is noted that the average grain size increases with increasing sintering temperature for $2 \mu \mathrm{m}$ at $1000^{\circ} \mathrm{C}$ up to $2.671 \mu \mathrm{m}$ at $1050^{\circ} \mathrm{C}$ then this size decreases slightly to $1100^{\circ} \mathrm{C}$ to reach the value of $2.51 \mu \mathrm{m}$; and the broader the granulo-metric distribution "Figure 2(b)", the more the size of the grains gets bigger. With increasing $\mathrm{P}_{2} \mathrm{O}_{5}$, the liquid-phase sintering dominated and was optimum for $4 \mathrm{wt} \% \mathrm{P}_{2} \mathrm{O}_{5}$ addition leading to maximum densification. The increase in grain size may have led to the decrease of oxygen vacancies in PZT [18]. Figure 2 also shows that the porosity decreases with the increase of sintering temperature (it reaches a minimum at $1050^{\circ} \mathrm{C}$ ), which is consistent with the increase of the densification of specimens.

\subsection{Phase Structure}

Sintered powders were examined by X-ray diffractometry to ensure phase purity and to identify the phases of the materials. The results of X-rays on the samples sintered at $1050^{\circ} \mathrm{C}$ are illustrated in Figure 3. The ceramics with various $\mathrm{P}_{2} \mathrm{O}_{5}$ contents all exist as pure perovskite phase. The ceramics exist as tetragonal phase which is indicated by the single $(002)_{\mathrm{T}}$ and $(200)_{\mathrm{T}}$ peak at $\mathrm{z}=0.00$ and $\mathrm{z}=0.02$. As $\mathrm{P}_{2} \mathrm{O}_{5}$ content increases from 4 to $8 \mathrm{wt} \%$, the ceramics coexist as tetragonal and rhombohedral phase revealed by the coexistence of $(002)_{\mathrm{T}}$ and $(200)_{\mathrm{R}}$ peaks in the $2 \theta$ range from $43.8^{\circ}$ to $45.3^{\circ}$. The ceramics with $\mathrm{z}=0.08$ and $\mathrm{z}=0.10$ exist as tetragonal phase revealed by the splitting of $(002) \mathrm{T}$ and $(200) \mathrm{T}$ peaks in the $2 \theta$ range from $43.5^{\circ}$ to $45.4^{\circ}$.

\subsection{Dielectric Properties}

The electrical properties were strongly dependent on the phase of the specimens. Figure 4 shows the dielectric constant $\varepsilon_{\mathrm{r}}$ and dielectric loss $\tan \delta$ of the ceramics sintered at $1050^{\circ} \mathrm{C}$ as a function of $\mathrm{P}_{2} \mathrm{O}_{5}$ content measured at $1 \mathrm{kHz}$. The temperature of the maximum dielectric constant $(T m)$ increased and the dielectric constant peak sharpened with increasing $\mathrm{P}_{2} \mathrm{O}_{5}$ concentration. Dielectric loss $\tan \delta$ slowly deceases at first (4 wt\%), and begins to increase when $\mathrm{P}_{2} \mathrm{O}_{5}$ content is up to $8 \mathrm{wt} \%$.

Figure 5 shows dielectric loss $(\tan \delta)$ of ceramics sintered at $1050^{\circ} \mathrm{C}$ as a function of $\mathrm{P}_{2} \mathrm{O}_{5}$ content it is noticeable that there is a variation of the dielectric losses 


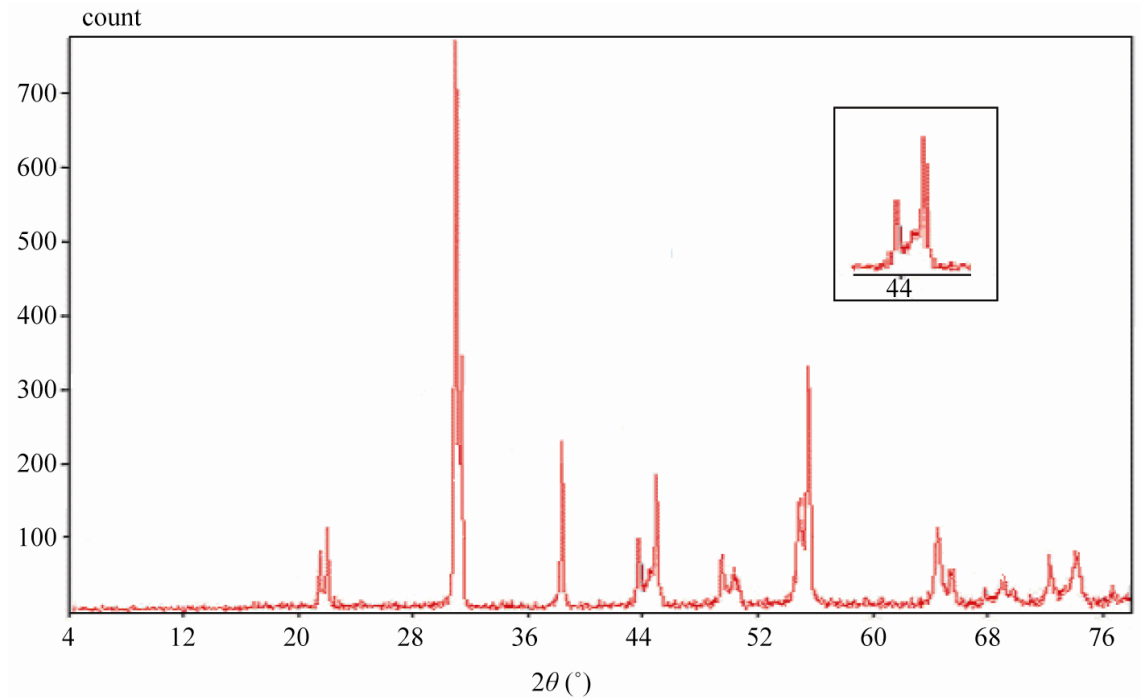

(a)

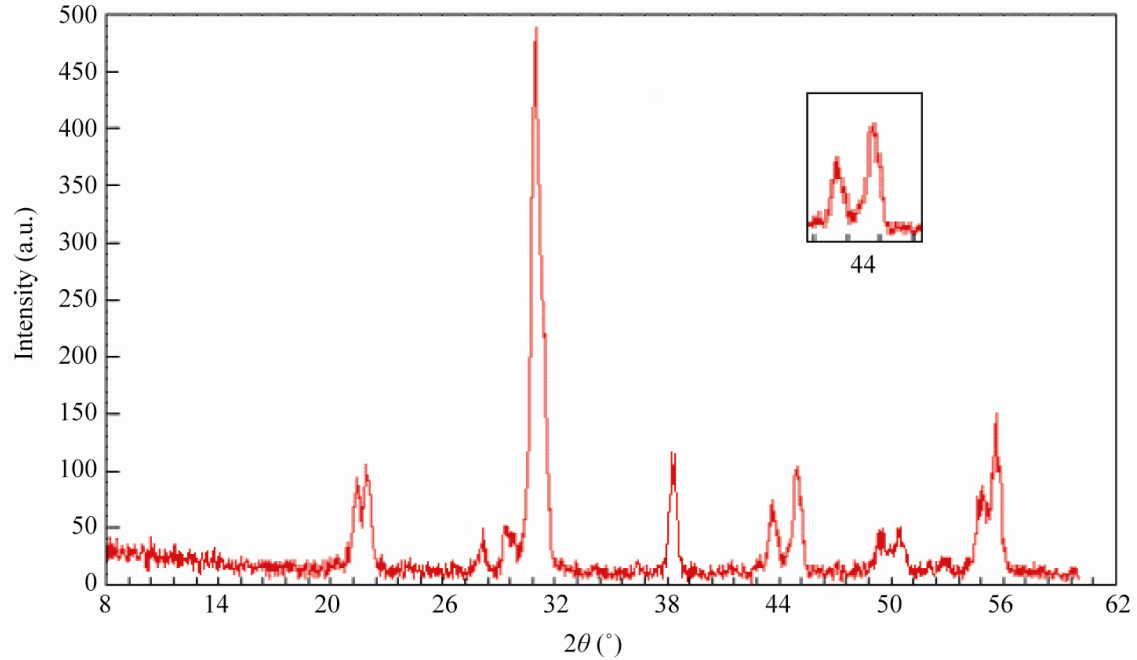

(b)

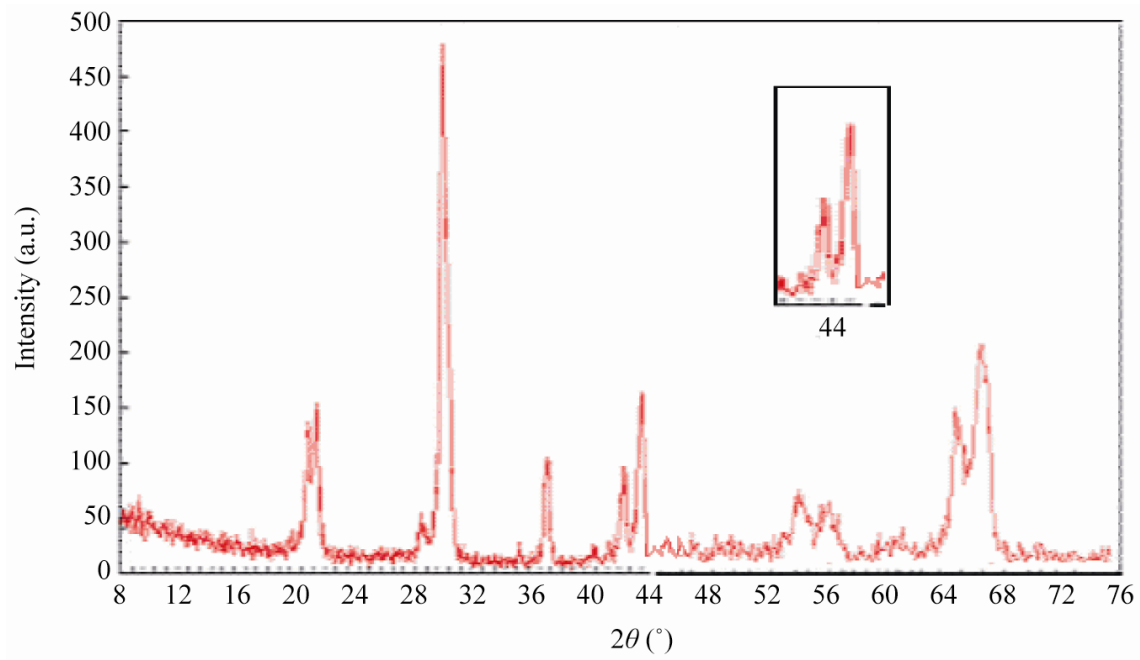

(c) 
$\mathrm{Pb}_{0.98} \mathrm{Ca}_{0.02}\left[\left\{\left(\mathrm{Zr}_{0.52} \mathrm{Ti}_{0.48}\right)_{0.98}\left(\mathrm{Cr}_{0.5}^{3+}, \mathrm{Ta}_{0.5}^{5+}\right)_{0.02}\right\}_{1-\mathrm{z}} \mathrm{P}_{\mathrm{z}}\right] \mathrm{O}_{3}$ Doping Effects

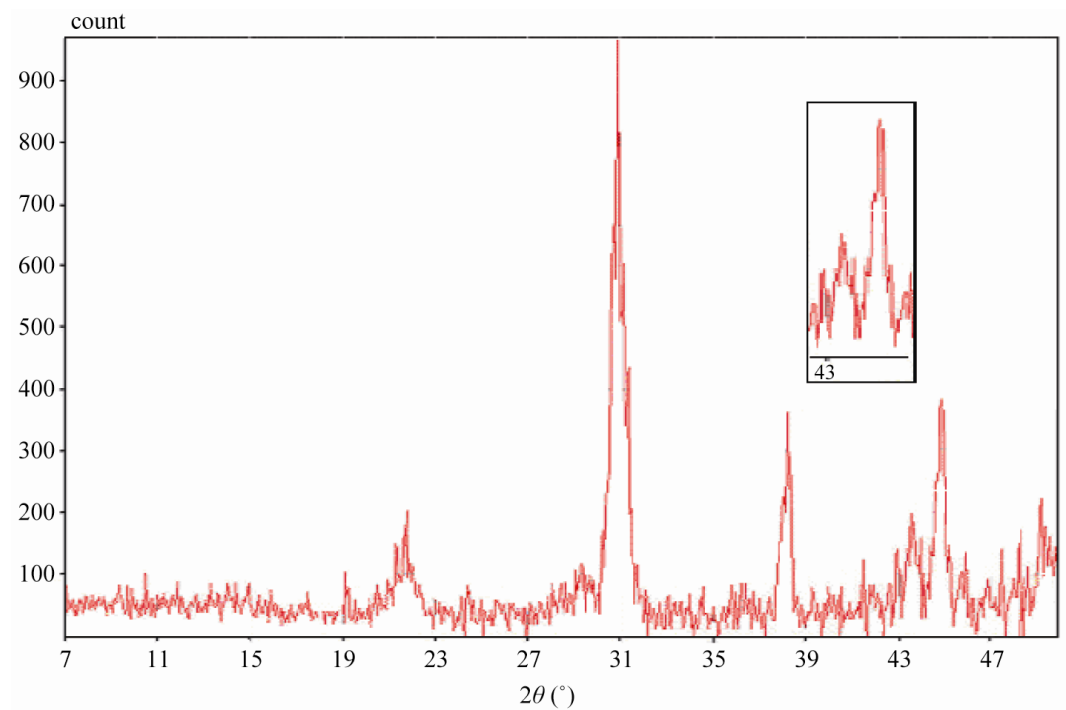

(d)

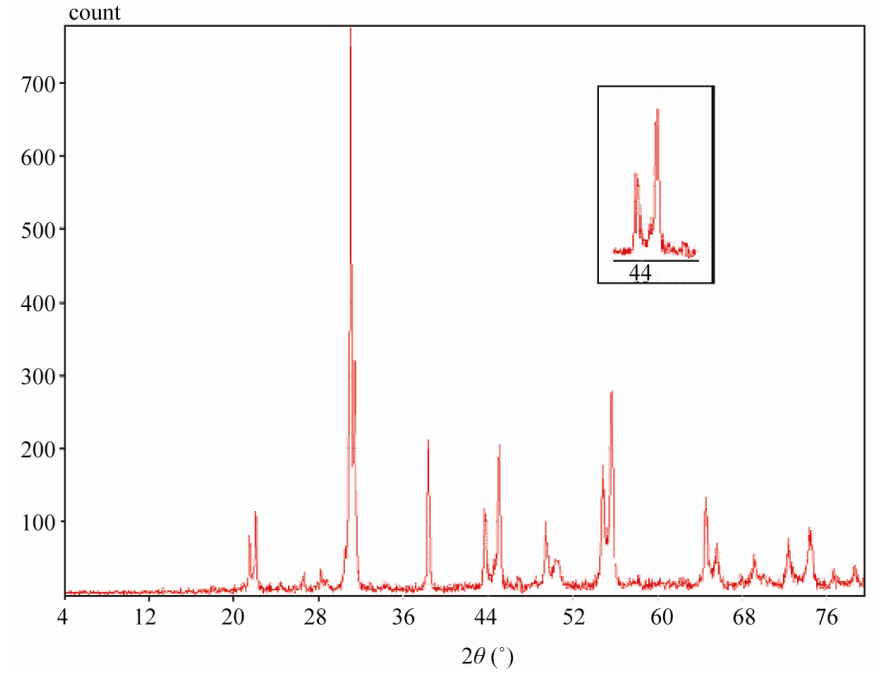

(e)

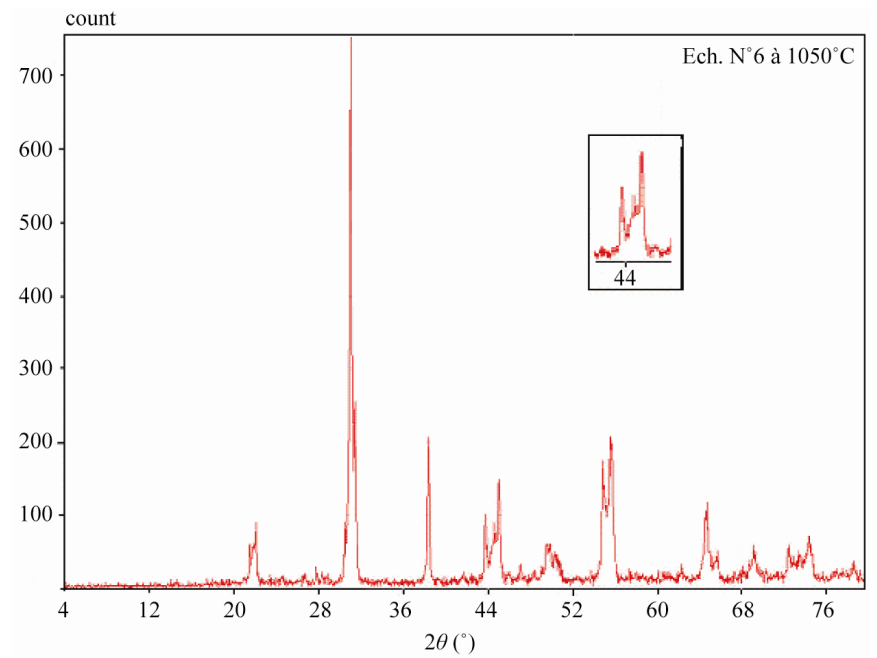

(f) 


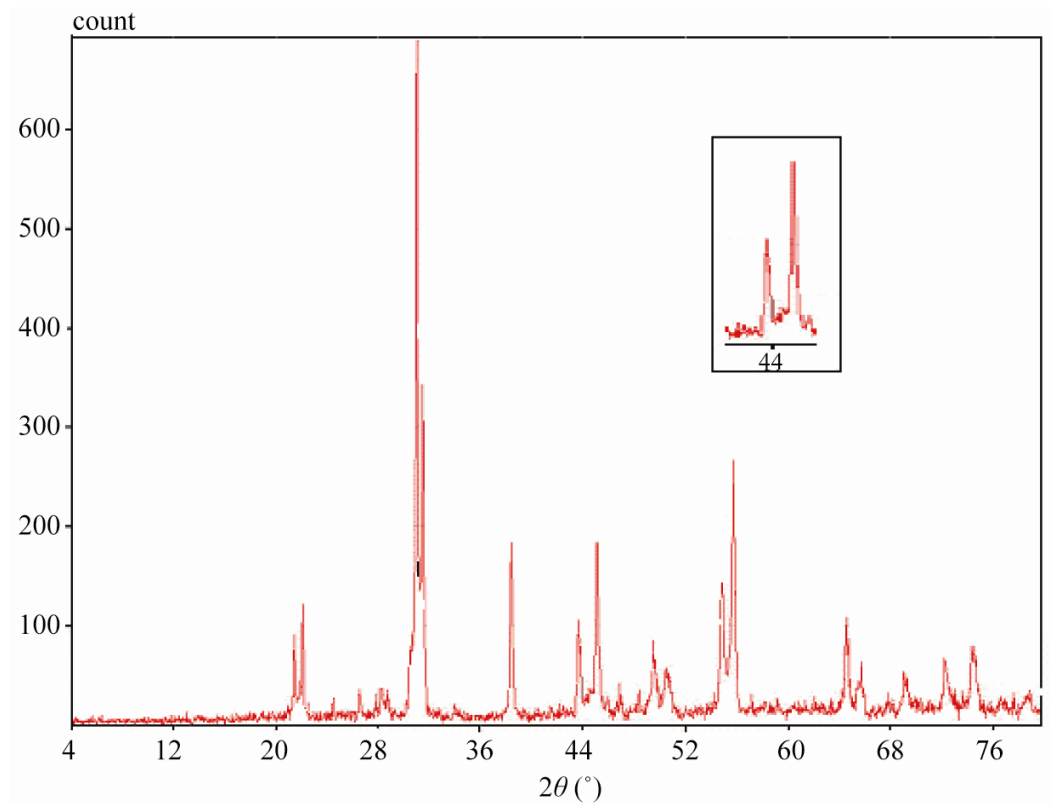

(g)

Figure 3. XRD patterns of sintered PZT-CCT ceramics with varying $\mathrm{P}_{2} \mathrm{O}_{5}$ addition: (a) 0 wt\%; (b) 2 wt \%; (c) 4 wt \%; (d) 6 wt \%; (e) $8 \mathrm{wt} \%$; (f) $10 \mathrm{wt} \%$ and (g) $12 \mathrm{wt} \%$ sintered at $1050{ }^{\circ} \mathrm{C}$.
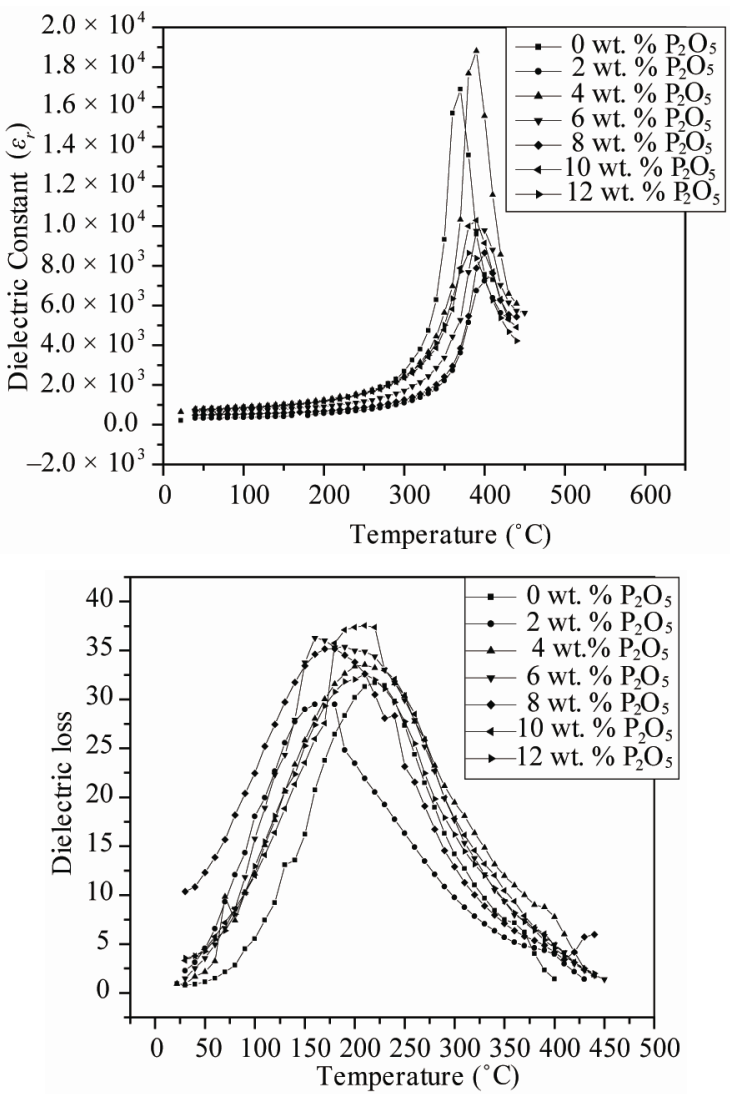

Figure 4. Temperature dependence of the dielectric constant $\varepsilon_{r}$ and dielectric loss $\tan \delta$ for perovskite $\mathbf{P b}_{\mathbf{0 . 9 8}} \mathbf{C a}_{0.02}$ $\left[\left\{\left(\mathrm{Zr}_{0.52} \mathbf{T i}_{0.48}\right)_{0.98}\left(\mathrm{Cr}_{0.5}^{3+}, \mathbf{T a}_{0.5}^{5+}\right)_{0.02}\right\}_{1-\mathrm{x}} \mathbf{P}_{\mathbf{x}}\right] \mathrm{O}_{3}$ ceramics.

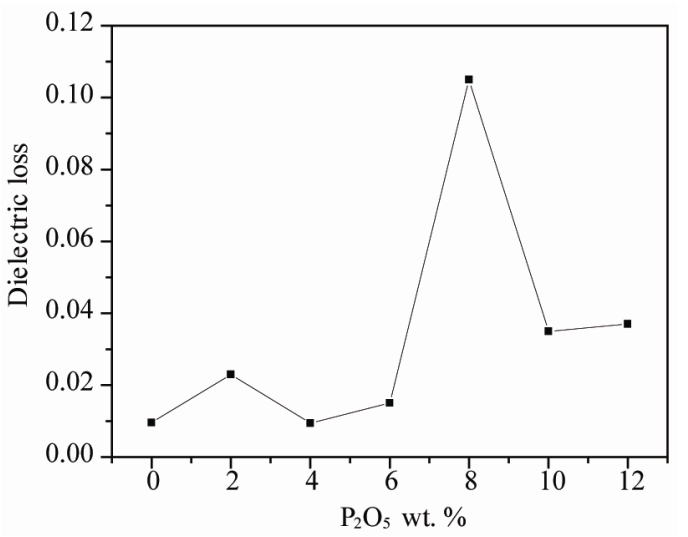

Figure 5. $\tan \delta$ of ceramics sintered at $1050^{\circ} \mathrm{C}$ as a function of concentration of $\mathrm{P}_{2} \mathrm{O}_{5}$.

with increasing concentration of $\mathrm{P}_{2} \mathrm{O}_{5}$. Dielectric loss $(\tan \delta)$ slowly deceases at first, and begins to increase when $\mathrm{P}_{2} \mathrm{O}_{5}$ content is up to $6 \mathrm{wt} \%$. This indicates that the compound doped with $4 \mathrm{wt} \%$ of $\mathrm{P}_{2} \mathrm{O}_{5}$ is denser than other doped.

The effects of $\mathrm{P}_{2} \mathrm{O}_{5}$ on the dielectric constant and dissipation factor measured at $1 \mathrm{kHz}$ are shown in Figure 6. The position of anomalies in the $\varepsilon_{r}$ and $\tan \delta$ curves, corresponding to $F_{\mathrm{R}(\mathrm{HT})}-P_{\mathrm{C}}$ phase transition, is dependent on the $\mathrm{P}_{2} \mathrm{O}_{5}$ content. The dielectric peak temperatures $(T \mathrm{c})$ shift slightly to lower temperatures with increasing $\mathrm{P}_{2} \mathrm{O}_{5}$ content. It is well known that $T \mathrm{c}$ varies with substitution. Therefore, the decrease in Tc can be explained by assumption that $\mathrm{P}_{2} \mathrm{O}_{5}$ substituted in the perovskite structure. 

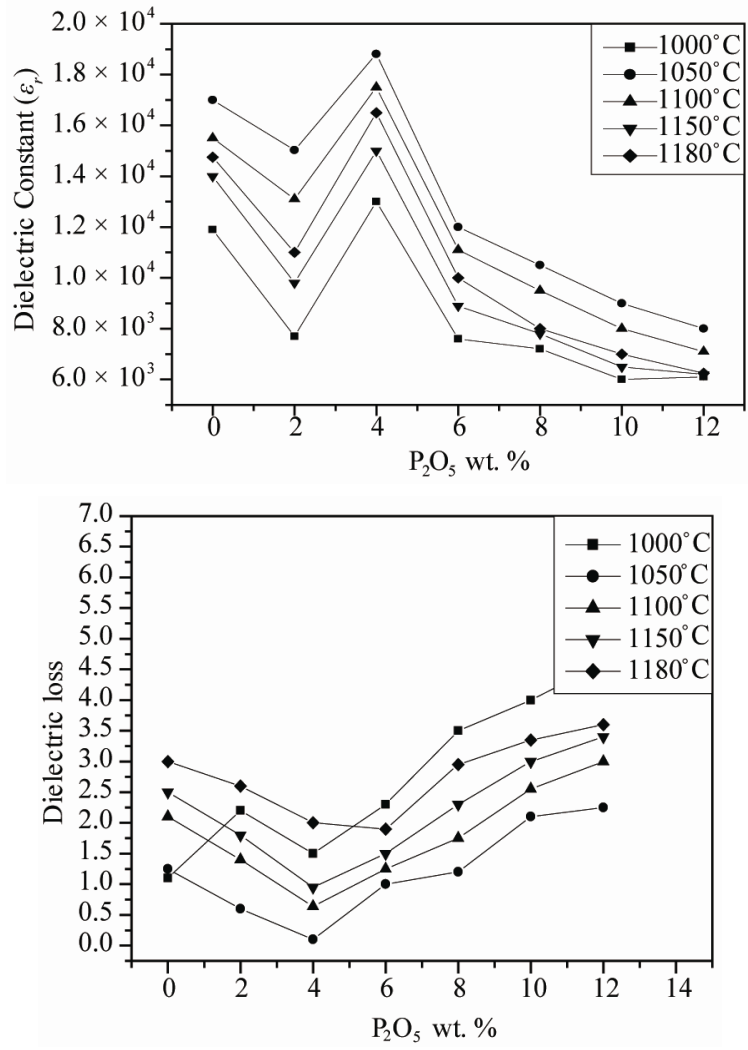

Figure 6. Evolution of the dielectric constant and dielectric loss $\tan \delta$ as a function of $\mathrm{P}_{2} \mathrm{O}_{5}$ additive at different sintering temperature.

The maxima in $\varepsilon_{r}$ curves become broadened when the $\mathrm{P}_{2} \mathrm{O}_{5}$ content exceeds $4.0 \mathrm{wt} \%$. The broadening or diffuseness of dielectric peaks occurs mainly due to the statistical composition fluctuations because large amount of the second phases appear in PZT ceramics. A statistical treatment based on a postulated Gaussian distribution of local Curie temperature is associated with the composition fluctuations [19].

The variation of the dielectric constant as a function of frequenc from $1 \mathrm{kHz}$ to $100 \mathrm{kHz}$ for $\mathrm{Pb}_{0.98} \mathrm{Ca}_{0.02}\left[\left\{\left(\mathrm{Zr}_{0.52}\right.\right.\right.$ $\left.\left.\left.\mathrm{Ti}_{0.48}\right)_{0.98}\left(\mathrm{Cr}_{0.5}^{3+}, \mathrm{Ta}_{0.5}^{5+}\right)_{0.02}\right\}_{1-\mathrm{x}} \mathrm{P}_{\mathrm{x}}\right] \mathrm{O}_{3}$ is illustrated in Figure 7. With the increase of frequency, dielectric constant varies moderately before $30 \mathrm{kHz}$, and then goes up abruptly. According to these results, we can consider the compound doped by $4 \mathrm{wt} \% \mathrm{P}_{2} \mathrm{O}_{5}$ as a ceramic soft (depolarize easily) and can be used at high frequencies in the transmission technology. Some authors explain the maximum value of the dielectric constant at room temperature and values of low frequency by the existence of different types of polarization [20,21].

\subsection{Electromechanical Properties}

The electrical properties were strongly dependent on the

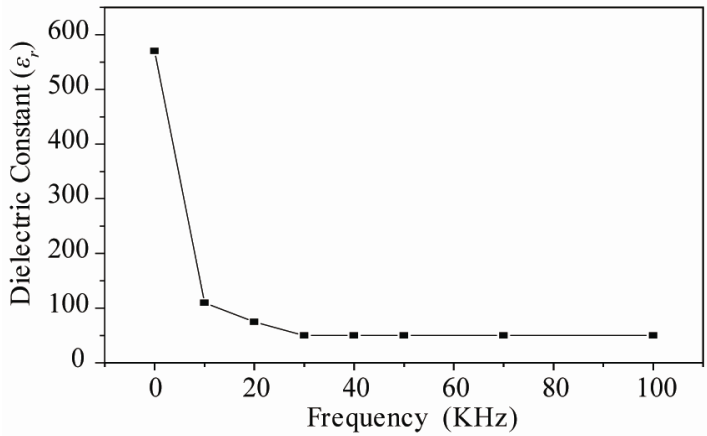

Figure 7. Evolution of the dielectric constant depending on the frequency for the sample doped by $4 \mathrm{wt} \%$ of $\mathrm{P}_{2} \mathrm{O}_{5}$.

phase of the specimens. The room-temperature electromechanical coupling factor $(k p)$ of $\mathrm{Pb}_{0.98} \mathrm{Ca}_{0.02}\left[\left\{\mathrm{Zr}_{0.52}\right.\right.$ $\left.\left.\left.\mathrm{Ti}_{0.48}\right)_{0.98}\left(\mathrm{Cr}_{0.5}^{3+}, \mathrm{Ta}_{0.5}^{5+}\right)_{0.02}\right\}_{1-\mathrm{z}} \mathrm{P}_{\mathrm{z}}\right] \mathrm{O}_{3}$ ceramics sintered at $1050^{\circ} \mathrm{C}$ as a function of $\mathrm{P}_{2} \mathrm{O}_{5}$ content is plotted in Figure 8. It can be observed that both of the $k p$ curve possess a peak with increasing $\mathrm{P}_{2} \mathrm{O}_{5}$ content. The $k p$ of $\mathrm{P}_{2} \mathrm{O}_{5}$ ceramics at $\mathrm{z}=0$ is $59.0 \%$. With increasing $\mathrm{P}_{2} \mathrm{O}_{5}$ content $(4$ $\mathrm{wt} \%$ ), the $k p$ of PZTMN ceramics reach their maximum values of $72.3 \%$

\subsection{Study of Resistivity and Conductivity}

The resistivity and conductivity of PZTMN sintered at $1050^{\circ} \mathrm{C}$ as a function of temperature are plotted in Figures 9 and 10, independently. It can be seen that both resistivity decrease monotonically with increasing temperature. The above variation of conductivity is different from resistivity shown in Figure 9. The curves of this figure show that there is a relationship between the relative change in temperature and the two electrical factors (conductivity and resistivity). More temperature increases, the resistivity of each sample decreases more and more (Figure 9(a)). It decreases for the sample of doped $4 \mathrm{wt} \%$.

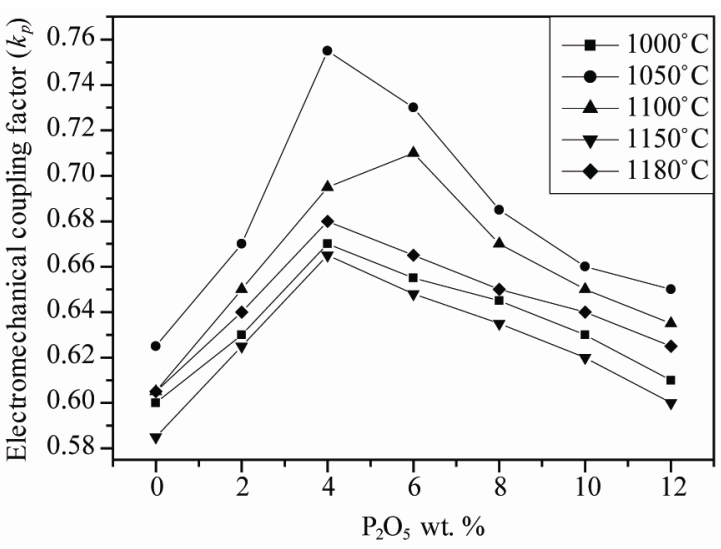

Figure 8. Evolution of $k_{p}$ as a function of $\mathrm{P}_{2} \mathrm{O}_{5}$ additive at different sintering temperature. 

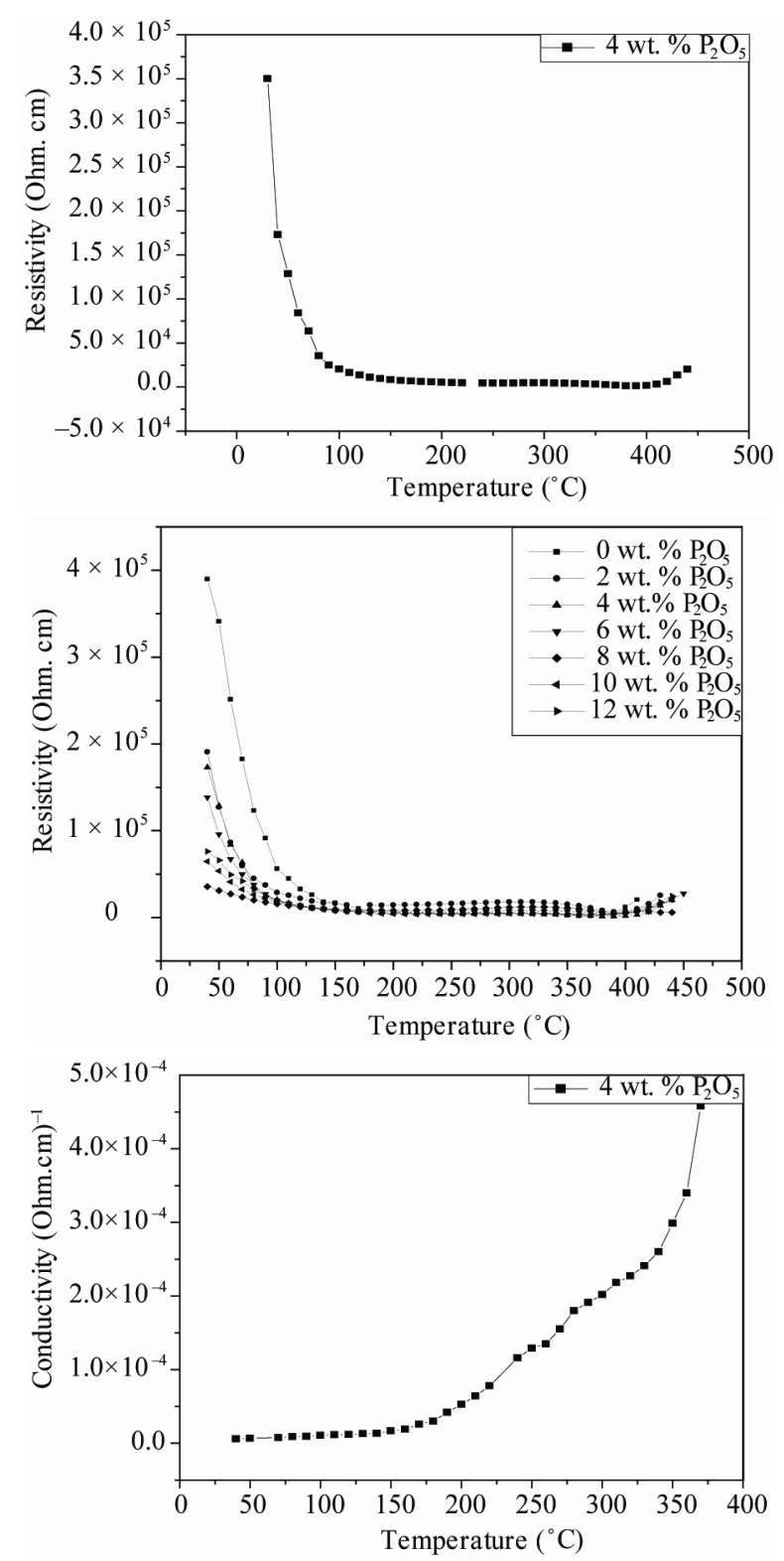

Figure 9. Variation in resistivity and conductivity sintered at $1050^{\circ} \mathrm{C}$ as a function of temperature.

$\mathrm{P}_{2} \mathrm{O}_{5}$ of $35 \times 10^{+4}(\Omega \cdot \mathrm{cm})$ when $\mathrm{T}=50^{\circ} \mathrm{C}$ until it reaches the value $0.09 \times 10^{+4}(\Omega \cdot \mathrm{cm})$ to $350^{\circ} \mathrm{C}$ (Figure 9 (b)). This is due to the fact that high-temperature thermal energy may be sufficient to break some connections or ionic and covalent causes some mobility of ions. However, the electrical conductivity varies in the opposite direction of resistivity; it grows with the increase of temperature (Figure 9(c)). It can reach a maximum value of $7.5 \times 10^{-4}(\Omega \cdot \mathrm{cm})^{-1}$ at a temperature of $350^{\circ} \mathrm{C}$.

\section{Conclusions}

The compounds of the solution solid zirconate-titanate

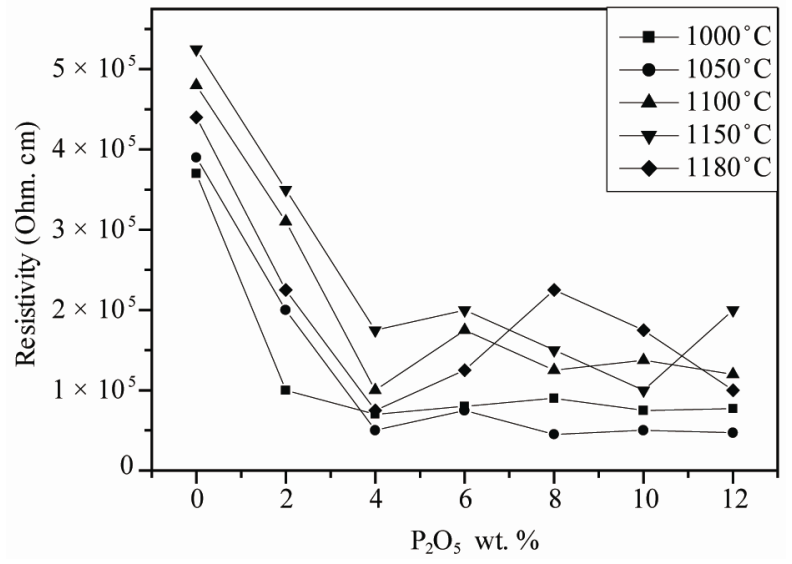

Figure 10. Evolution of the resistivity as a function of $\mathrm{P}_{2} \mathrm{O}_{5}$ additive at different sintering temperature.

Table 1. Dielectric and piezoelectric properties of PZTMN doped with $4 \mathrm{wt} \%$ of $\mathrm{P}_{2} \mathrm{O}_{5}$ and sintered at $1050{ }^{\circ} \mathrm{C}$.

\begin{tabular}{cccccc}
\hline properties & $\mathrm{d}\left(\mathrm{g} / \mathrm{cm}^{3}\right)$ & $\varepsilon_{r}$ & $\tan \delta$ & $\rho(\Omega \cdot \mathrm{cm})$ & $\mathrm{k}_{\mathrm{p}}(\%)$ \\
\hline values & 7.6 & 18800 & 0.0094 & $0.09 \times 10^{4}$ & 0.73 \\
\hline
\end{tabular}

lead, noted PZT, general formula $\mathrm{Pb}_{0.98} \mathrm{Ca}_{0.02}\left[\left\{\mathrm{Zr}_{0.52}\right.\right.$ $\left.\left.\left.\mathrm{Ti}_{0.48}\right)_{0.98}\left(\mathrm{Cr}_{0.5}^{3+}, \mathrm{Ta}_{0.5}^{5+}\right)_{0.02}\right\}_{1-\mathrm{z}} \mathrm{P}_{\mathrm{z}}\right] \mathrm{O}_{3}$ as $\mathrm{z}$ vary from 0.00 to 0.12 by setup of 0.02 , it has been prepared from a mixture of oxides by the method ceramics. The effect of sintering temperature on density and porosity was studied to achieve the optimum sintering temperature corresponding to the maximum density and minimum value of porosity, because this temperature $\left(1050^{\circ} \mathrm{C}\right)$ corresponds to a better quality product. Low-temperature densification of PZT can be achieved by the incorporation of a small amount of $\mathrm{P}_{2} \mathrm{O}_{5}$ as a sintering aid without sacrificing the dielectric properties.

The preferable sintering temperature was about $1050^{\circ} \mathrm{C}$ and presented the maximum bulk density of $7.62 \mathrm{~g} / \mathrm{cm}^{3}$. The study of dielectric properties and piezoelectric of this compound in the solid as a function of temperature allows us to have high values of dielectric constant and planar electromechanical coupling factor at $z=0.04$. The results of measurement of dielectric and piezoelectric properties of this material are reported in the Table 1.

\section{REFERENCES}

[1] G. H. Haertling, "Ferroelectric Ceramics: History and Technology," Journal American Ceramic Society, Vol. 82, No. 4, 1999, pp. 797-818. doi:10.1111/j.1151-2916.1999.tb01840.x

[2] K. Uchino, "Ferroelectric Device," Marcel Dekker, New York, 2000.

[3] S. Y. Cheng, S. L. Fu, C. C. Wei and G. M. Ke, "The Pro- 
perties Low-Temperature Fixed Piezoelectric Ceramics," Journal of Materials Science, Vol. 21, No. 2, 1986, pp. 571-576. doi:10.1007/BF01145525

[4] H. G. Lee, J. H. Choi and E. S. Kim, ” Low-Temperature Sintering and Electrical Properties of $(1-x) \mathrm{Pb}\left(\mathrm{Zr}_{0.5} \mathrm{Ti}_{0.5}\right)$ $\mathrm{O}_{3}-x \mathrm{~Pb}\left(\mathrm{Cu}_{0.33} \mathrm{Nb}_{0.67}\right) \mathrm{O}_{3}$ Ceramics," Journal of Electroceramics, Vol. 17, No. 2-4, 2006, pp. 1035-1040. doi:10.1007/s10832-006-0384-1

[5] R. Mazumder, A. Sen and H. S. Maiti, "Impedance and Piezoelectric Constants of Phosphorous-Incorporated $\mathrm{Pb}-$ $\left(\mathrm{Zr}_{0.52} \mathrm{Ti}_{0.48}\right) \mathrm{O}_{3}$ Ceramics," Materials Letters, Vol. 58, No. 25, 2004, pp. 3201-3205. doi:10.1016/j.matlet.2004.06.011

[6] G. Robert, M. D. Maeder, D. Damjanovic and N. Setter, "Synthesis of Lead Nickel-Niobate Zirconate Titanate Solid Solutions by a B-Site Precursor," Journal American Ceramic Society," Vol. 84, No. 12, 2001, pp. 2863-2868. doi:10.1111/j.1151-2916.2001.tb01107.x

[7] L. Pdungsap, S. Boonyeun, P. Winotai, N. Udomkan and P. Limsuwan, "Effects of $\mathrm{Gd}^{3+}$ Doping on Structural and Dielectric Properties of PZT ( $\mathrm{Zr}: \mathrm{Ti}=52: 48)$ Piezoceramics," The European Physical Journal B, Vol. 48, No. 3, 2005, pp. 367-372. doi:10.1140/epjb/e2005-00407-9

[8] S. J. Yoon, A. Joshi and K. Uchino, "Effect of Additives on the Electromechanical Properties of $\mathrm{Pb}(\mathrm{Zr}, \mathrm{Ti}) \mathrm{O}_{3}-\mathrm{Pb}-$ $\left(\mathrm{Y}_{2 / 3} \mathrm{~W}_{1 / 3}\right) \mathrm{O}_{3}$ Ceramics," Journal of the American Ceramic Society, Vol. 80, No. 4, 2005, pp. 1035-1039. doi:10.1111/j.1151-2916.1997.tb02942.x

[9] G. A. Smolenskii and A. I. Agranovskaya, "Dielectric Polarization of a Number of Complex Compounds," Soviet Physics Solid State, Vol. 1, No. 10, 1960, pp. 1429-1437.

[10] F. Kulcsar, "Electromechanical Properties of Lead Titanate Zirconate Ceramics Modified with Tungsten and Thorium," Journal American Ceramic Society, Vol. 48, No. 1, 1965, pp. 48-54. doi:10.1111/j.1151-2916.1965.tb11796.x

[11] N. Abdessalem and A. Boutarfaia, "Effect of Composition on the Electromechanical Properties of $\mathrm{Pb}\left[\mathrm{Zr}_{\mathrm{x}} \mathrm{Ti}_{(0.9-\mathrm{x})^{-}}\right.$ $\left.\left(\mathrm{Cr}_{1 / 5}, \mathrm{Zn}_{1 / 5}, \mathrm{Sb}_{3 / 5}\right)_{0.1}\right] \mathrm{O}_{3}$ Ceramics," Ceramics International, Vol. 33, No. 2, 2007, pp. 293-296. doi:10.1016/j.ceramint.2005.08.008

[12] J. S. Kim and K. H. Yoon, "Physical and Electrical Properties of $\mathrm{MnO}_{2}$-Doped $\mathrm{Pb}\left(\mathrm{Zr}_{x} \mathrm{Ti}_{1-x}\right) \mathrm{O}_{3}$ Ceramics," Journal of Materials Science, Vol. 29, No. 3, 1994, pp. 809-815. doi:10.1007/BF00445997

[13] P. Duran, J. F. Fernandez and C. Moure, "Effect of MnO Additions on the Sintering and Piezoelectric Properties of Samarium-Modified Lead Titanate Ceramics," Journal of Materials Science Letters, Vol. 10, No. 15, 1991, pp. 917919. doi:10.1007/BF00724781

[14] Z. He, J. Ma, R. Z. Hang, "Investigation on the Microstructure and Ferroelectric Properties of Porous PZT Ceramics," Ceramics International, Vol. 30, No. 7, 2004, pp. 1353-1356. doi:10.1016/j.ceramint.2003.12.108

[15] R. Sumang and T. Bongkarn, "The Effect of Excess PbO on Crystal Structure, Microstructure, Phase Transition and Dielectric Properties of $\left(\mathrm{Pb}_{0.75} \mathrm{Sr}_{0.25}\right) \mathrm{TiO}_{3}$ Ceramics," Taylor \& Francis Group LLC, Vol. 403, No. 1, 2010 , pp. 82-90. doi:10.1080/00150191003748949

[16] P. Goel, S. Sharma, K. L. Yadav and A. R. James, "Structural and Dielectric Properties of Phosphorous-Doped PLZT Ceramics," Pramanas, Vol. 65, No. 6, 2005, pp. 1127-1132. doi:10.1007/BF02705288

[17] A. K. Saha, D. Kumar, O. Parkash, A. Sen and H. S. Maiti, "Effect of Phosphorus Addition on the Sintering and Dielectric Properties of $\mathrm{Pb}\left(\mathrm{Zr}_{0.52} \mathrm{Ti}_{0.48}\right) \mathrm{O}_{3}$," Materials Research Bulletin, Vol. 38, No. 7, 2003, pp. 1165-1174. doi:10.1016/S0025-5408(03)00112-0

[18] O. Ohtaka, R. Von Der Mühll and J. Ravez, "Low-Temperature Sintering of $\mathrm{Pb}(\mathrm{Zr}, \mathrm{Ti}) \mathrm{O}_{3}$ Ceramics with the Aid of Oxyfluoride Additive: X-Ray Diffraction and Dielectric Studies," Journal American Ceramic Society, Vol. 78, No. 3, 1995, pp. 805-808. doi:10.1111/j.1151-2916.1995.tb08251.x

[19] W. Heywang, "Ferroelektrizität in Perowskitischen Systemen und Ihre Technischen Anwendungen," Zeitschrif Angewandte Physik, Vol. 19, 1965, pp. 473-481.

[20] S. Babu, D. Singh and A. Govindan, "Electrical Properties of Calcium Modified PZT System," International Journal of Computer Science et Technologie, Vol. 2, No. 1, 2011, pp. 128-131.

[21] IEEE Standard on Piezoelectricity, IEEE Standard 1761978, Institute of Electrical and Electronic Engineers, New York, 1978. 